\title{
O Brasil e a América Latina: Opções Políticas e Integração Regional ${ }^{(*)}$
}

\author{
Shiguenoli Miyamoto(*)
}

\begin{abstract}
Resumo: O tex to examina o papel da integração e da América do Sul na agenda da política externa do Brasil. Esses dois itens sempre fizeram parte das preocupações brasileiras, independentemente do tempo, dos governantes e dos regimes políticos. Procuramos, ao longo do artigo, mostrar os interesses e as prioridades estabelecidas pelas autoridades brasileiras, por meio da instância responsável pelas relações exteriores, aos diversos itens que compõem a agenda nacional, sobretudo no que diz respeito à atuação regional. Fazemos algumas digressões tanto no plano diplomático quanto no estratégico-militar, dando ênfase às últimas décadas, quando a integração passou a ocupar espaço importante na pauta brasileira e na dos demais países sul-americanos, a partir da criação da Associação Latino-Americana de Livre Comércio (ALALC). Nossa preocupação não é, contudo, analisar detidamente qualquer uma das iniciativas em particular, mas, sim, as prioridades globais do governo brasileiro nos diversos momentos.
\end{abstract}

Palavras-chave: Política Externa Brasileira, Integração Regional, Integração Sul-Americana, América Latina, América do Sul.

\begin{abstract}
The text examines the role of integration and South America in the Brazilian foreign policy agenda. These two items have always been Brazilian concerns regardless of time, governments and political regimes. Throughout this paper we demonstrate interests and priorities that were established by Brazilian institution responsible for foreign policy on the diverse items which constitute the national agenda, especially in regards to regional initiatives. We analyzed diplomatic and political-military issues focusing on recent decades when integration became an important theme in the Brazilian and in other South American countries' agenda because of the Latin American Free Trade Association (Associação Latino-Americana de Livre Comércio - ALALC). Our concern is not, however, to analyze deeply any specific initiatives, but to focus on the Brazilian government's overall priorities at each moment.
\end{abstract}

Keywords: Brazilian Foreign Policy, Regional Integration, South American Integration, Latin America, South America.

\footnotetext{
(*) Versão revisada e ampliada de texto apresentado no IV Congresso da Associação Latino-Americana de Ciência Política (ALACIP), realizado na Universidade da Costa Rica, de 5 a 7 de agosto de 2008 . A produção deste texto e a participação no evento contaram com recursos do $\mathrm{CNPq}$, por intermédio de Bolsa de Produtividade em Pesquisa (nível 1B) concedida ao autor

(**) Professor Titular em Relações Internacionais e Política Comparada do Departamento de Ciência Política do Instituto de Filosofia e Ciências Humanas da Universidade Estadual de Campinas. Email: shiguenoli@gmail.com ou shigue@unicamp.br. Recebido em 6.4.09 e aceito em 27.5.09.
} 


\section{INTRODUÇão}

Qual o espaço ocupado pela integração e pela América do Sul na agenda da política externa brasileira? Essa é uma pergunta, ou dúvida, que vez ou outra é formulada pelos países da região, mas que não tem encontrado dificuldades em ser respondida pelas autoridades brasileiras: o continente sul-americano sempre foi, continua e permanecerá sendo importante para o Brasil. Tal afirmação, porém, não deve, necessariamente, ser confundida ou entendida como prioritária. Ou seja, parte-se do pressuposto que nada é imutável e que todas as políticas alteram-se de acordo com as conjunturas ou com os interesses, e tal comportamento se aplica a todos os países e todas as regiões do mundo.

Ao atuar neste que é o cenário ao qual geograficamente pertence, e tem fronteiras de mais de 15 mil quilômetros com dez nações, o Brasil tem sido frequentemente acusado de conduzir políticas agressivas, em busca de uma liderança nesta parte do mundo. As ressalvas e desconfianças muitas vezes têm sua razão de ser. Em oportunidades diversas, pronunciamentos e declarações tanto do presidente da República quanto de membros do corpo diplomático e estrategistas têm levantado suspeitas sobre as reais intenções do Brasil, quando o governo propõe ou procura elaborar políticas visando a agregar as nações sul-americanas em torno de um ideal comum.

Rótulos de imperialismo, sub-imperialismo e outros de semelhante calibre têm sido utilizados ao longo do tempo, de forma recorrente, para denunciar o governo brasileiro. ${ }^{(1)}$ Tal comportamento pode ser entendido como normal, se considerarmos a forma como se construiu o território brasileiro e as assimetrias existentes entre os países que fazem parte do continente sul-americano, bastante visíveis sob todos os aspectos.

Independentemente do que pensam os vizinhos, o que se pode destacar, sem qualquer sombra de dúvida, é que a América do Sul sempre foi o palco primeiro da atuação nacional, ainda que sofrendo flutuações, dependendo dos momentos e do regime vigente. ${ }^{(2)}$

Não seria enganoso afirmar que, tanto mais o país apresente avanços em seus indicadores econômicos, sociais e estratégicos, proporcionalmente surgirão acusações de falta de solidariedade brasileira para com os vizinhos menos favorecidos. Isso significaria dizer o seguinte: embora haja ressalvas com relação a um papel hegemônico que o Brasil poderia reivindicar na região, os demais países conferem legitimidade a esse fato, sabendo de sua inevitabilidade, ainda que essa não seja a realidade atual. Exigirão, entretanto, em contrapartida, que para o Brasil exercitar uma liderança não contestada deverá auxiliar no desenvolvimento dos demais, porque, afinal de contas, esse é o papel do líder, e o preço que deve pagar aquele que a tal se propõe.

Uma das explicações para tal comportamento poderia ser encontrada no fato de que praticamente todas as nações sul-americanas padecem, ainda, de estruturas mais sólidas,

(1) Cf. por exemplo, Botelho (1974). Mais recentemente, as afirmações do então candidato paraguaio à presidência da República, Fernando Lugo, e de Evo Morales.

(2) A esse propósito, ver a série recente de reportagens da BBC sobre o que pensam do Brasil, os seus vizinhos sulamericanos (BBC BRASIL, 2008). 
em todos os níveis, prestando-se a políticas personalistas de um ou outro governante que faz uso do cargo para projetar-se, colocando os assuntos nacionais em segundo plano, ainda que retoricamente afirme o contrário, e clamando por uma unidade continental.

Quer dizer, por razões como essas, o processo de integração regional caminha a passos mais lentos do que o desejado. Isso pode ser creditado não apenas a um ou outro governo, mas também por causa, certamente, da tentativa de afirmação de países que aspiram a jogar papel maior no continente, não deixando de lado tais pretensões, enquanto o quadro não for definitivamente desenhado, o que de resto é perfeitamente compreensível, se pensarmos nas disputas ocorridas para formatar cada um dos Estados da região.

Enquanto as estruturas sociais e econômicas não se solidificarem, a questão da integração regional encontrará dificuldades, como tem acontecido no último meio século, ainda que algumas iniciativas sejam tomadas. Apesar disso, e mesmo por causa de, o Brasil tem investido em políticas de cooperação que oscilam de acordo com o tempo, com as conjunturas domésticas e regionais, ora conferindo mais ênfase, ora não dando a devida importância à integração como elemento-motor no relacionamento com seus vizinhos. É bem verdade que o mesmo se aplica para o outro lado.

Não é difícil encontrar razoável número de argumentos que defendem a cooperação e a integração como o melhor caminho para um ganho coletivo, de todos os países que fazem parte do continente sul-americano, por meio de políticas de desenvolvimento compartilhadas. Com essa perspectiva, dever-se-ia romper com as velhas estruturas que bloqueiam a melhoria de condições gerais, em todos os níveis. Inúmeros fatores - e até agora difíceis de serem superados — devem, obviamente, ser ponderados. A responsabilidade pela situação vivida pelo continente, certamente, não pode ser outorgada a fatores estritamente geopolíticos, ou seja, a interpretações enviesadas que os consideram como determinantes para que a região permaneça nas condições usufruídas, não apenas neste momento, mas também historicamente..$^{(3)}$

Como apresentaremos nos parágrafos seguintes, o tema da integração regional sempre se fez presente na pauta da política externa brasileira, da mesma forma que a América do Sul como um todo. As dificuldades encontradas para alcançar uma cooperação maior no Cone Sul, com os países andinos ou amazônicos, em grande parte têm sido resultado da própria falta de vontade política de seus membros como um todo, e não apenas de voluntarismos de um ou outro.

Em momentos distintos, barreiras têm sido levantadas por motivações distantes de favorecer diálogos coletivos, que têm impedido o progresso mais generoso das políticas de cooperação, em nível geral, do subcontinente. Em poucas oportunidades têm sido observadas coincidências no trato de problemas específicos e regionais. Pelo contrário, quase sempre um tema que afeta um dos membros dessa comunidade não apresenta necessariamente o mesmo significado para outro. Nesse sentido, o tema da integração regional tem sido frequentemente penalizado, adquirindo mais força no plano da retórica do que colocado

(3) Sobre essa questão, consultar o relatório do BID coordenado por Hausmann (2000). Assim que foi divulgado, o relatório mereceu críticas intensas. 
na prática, buscando cada país, de forma individual, as alternativas que considera melhores para resolver seus próprios problemas.

\section{Diretrizes DA POLÍTICA EXTERNA BRASILEIRA}

Historicamente, a atenção do Brasil esteve todo o tempo voltada para a Bacia do Prata. Não são necessárias muitas explicações para entender tal fato. Desde o Tratado de Tordesilhas (1494), que dividiu o continente sul-americano entre os reinos lusitano e hispânico, o território brasileiro só fez aumentar em todas as direções: para o Norte, o Sul e para Oeste, mais do que dobrando o espaço original. Na Colônia e no Império, praticamente se configurou o território nacional tal como o conhecemos. Apenas o antigo território do Acre foi incorporado à República recente, adquirido do governo boliviano no início do século passado.

Conforme o território luso-brasileiro foi crescendo, divergências foram observadas com seus vizinhos, principalmente ao Sul que, igualmente, afirmavam-se geograficamente, constituindo novos Estados. Nesse meio tempo, tratados inúmeros foram assinados, inclusive para legalizar e legitimar as investidas feitas tanto pelas entradas quanto pelas bandeiras que, cada vez mais, adentravam ao hinterland latino-americano (ROMAN BLANCO, 1966; TAUNAY, 1975; BUARQUE DE HOLANDA, 1976, 1994).

A literatura que explica a evolução das instituições políticas e a formação dos territórios dos estados sul-americanos é ampla, sob todos os pontos de vista, e produzida tanto para dar conta de suas realidades internas quanto para entender o que se passou com os demais vizinhos que da região fazem parte.

Como não poderia deixar de ser, em grande medida, a literatura brasileira realça as motivações gloriosas que orientaram as iniciativas tomadas durante os séculos que se seguiram ao Tratado de Tordesilhas. O mesmo se verifica nas décadas mais próximas, com o engrandecimento do país e a busca pelo status de grande potência ou potência emergente. Pelo lado dos vizinhos, a interpretação sobre o Brasil certamente trilha caminhos diferentes e está longe de adotar os mesmos critérios aqui utilizados; pelo contrário, ressalta-se sempre as políticas expansionistas conduzidas pelos lusitanos e brasileiros para explicar os motivos pelos quais o continente chegou ao atual mapa.

Enquanto o "mundo era menor", a Bacia do Prata se converteu, sem qualquer sombra de dúvida, no lócus privilegiado da atuação brasileira. Basta aqui relembrarmos a forte atenção concedida pelo Império, na defesa dos interesses nacionais, combatendo Francisco Solano Lopez na Guerra do Paraguai (1864-1870), evento no qual aquele país saiu inteiramente destroçado (CANCOGNI, BORIS, 1975; POMER, 1981; DORATIOTO, 2002).

O resto do continente sul-americano durante muito tempo pareceu relegado a plano secundário. Na realidade, não foi isso, que aconteceu, mas, pelo fato de no Cone Sul se encontrarem os dois maiores rivais do Brasil, a política externa priorizou essa parte do continente como centro de suas preocupações. Ali as fronteiras sempre foram mais 
conflituosas, apresentando, portanto, maior risco do que na região Norte. Nessa última, os países com os quais o Brasil estabelece linhas divisórias estiveram de costas para cá, mirando mais para o Oceano Pacífico e o Caribe. As grandes florestas se converteram nos limites naturais entre todas as nações amazônicas e, potencialmente, alvos menores de divergências, quando assuntos outros de maior envergadura se faziam presentes ao longo do Rio Paraná.

Na Bacia do Prata, as disputas registradas pela História mostram claramente concepções diferentes sobre o que deveria prevalecer no vértice sul americano, com países dotados de espíritos diferentes, com populações que se formaram a partir de colonizações não coincidentes: uma que resultou de uma forte influência local, outra mais próxima do velho mundo, enquanto no país de maiores dimensões geográficas verificou-se miscigenação dificilmente encontrada em qualquer parte do mundo. Portanto, todas bastante distintas entre si, pelo menos culturalmente.

No decorrer do tempo, enquanto os Estados Nacionais locais se fortaleceram, cada um buscando seu próprio destino, críticas diversas foram feitas ao governo brasileiro, por esse adotar, em princípio, políticas não condizentes com as necessidades/realidades locais, procurando exercer papel de predomínio continental, transformando-se, assim, em país hegemônico.

Não se pode negar, do lado brasileiro, que podem ser observadas propostas nem sempre consideradas simpáticas pelos vizinhos, formuladas não apenas por diplomatas, mas fundamentalmente por militares e profissionais ligados aos mais diferentes setores, apoiadas em concepções geopolíticas de projeção continental. Muitos escritos defendem, sem nuances, a necessidade de fazer do país um Estado dotado de forte poder, para, consequentemente, achar-se apto a desempenhar as funções de grande líder sul-americano, cumprindo, assim, seu destino histórico e incontestável de maior nação regional.

Obviamente, propostas e discursos com esse conteúdo, às vezes mais agressivos, por parte de representantes brasileiros, não obtiveram resposta favorável a tais modos políticos de pensar. Pelo contrário, criou-se um discurso defensivo e adverso dirigido contra as pretensões brasileiras. O que se pode notar são duas concepções em termos do discurso regional. Do lado brasileiro, a existência de propostas concretas de ocupação do território nacional, com políticas de integração e interiorização, projetando suas influências políticas, econômicas e culturais, além das fronteiras, portanto, afetando a todo o continente, já que sozinho ocupa metade desse. Por parte dos vizinhos, percebe-se a construção de um discurso reativo às propostas brasileiras, não se conseguindo fazer com a mesma eficácia projetos para contraporem-se de forma direta às iniciativas brasileiras. Dos autores mais conhecidos e citados na bibliografia latino-americana, pode ser ressaltado o quarteto formado por Mário Travassos, Golbery do Couto e Silva, Carlos de Meira Mattos e Therezinha de Castro, considerados os grandes geopolíticos brasileiros.

Desses, que não apenas se restringiram a analisar, mas principalmente fizeram propostas de integração nacional e projetaram o poder nacional, considerando as fronteiras como isóbaras políticas, Mário Travassos é, sem qualquer sombra de dúvida, apontado como precursor das tendências hegemônicas no plano regional. A obra desse autor que, 
justamente em função de seu verdadeiro objetivo, passou a ser chamada de Proję̧ão Continental do Brasil é elucidativa já a partir do próprio título. ${ }^{(4)}$ Sua análise não se limitou apenas a propor políticas de ocupação exclusivamente no plano nacional, mas, sim, englobou o continente sul-americano, em uma visão ampla, que contemplava a América do Sul como um todo, do Prata à Bacia Amazônica, do Atlântico ao Pacífico, focando seus olhares no heartland latino-americano, situado em território boliviano, composto pelo triângulo Sucre - Cochabamba - Santa Cruz de la Sierra. ${ }^{(5)}$

A proposta de Therezinha de Castro com a teoria de defrontação, sobre a ocupação da Antártica, também não passou impune e mereceu críticas ácidas principalmente em território argentino. ${ }^{(6)}$ Segundo os ideais dessa autora, a região antártica deveria pertencer aos países que lá tivessem bases, dividindo-se o continente em fatias como uma gigantesca pizza gelada, projetando-se linhas das extremidades mais externas de cada país até o centro da Antártica.

Aliás, é da nação portenha que provieram as grandes críticas relacionadas ao comportamento brasileiro, fazendo-as não apenas para as políticas internas, mas, sobretudo, àquelas voltadas para o continente como um todo. A perspectiva conspirativa sempre permeou a ótica dos autores argentinos, numerosos, por sinal, e de outros países vizinhos, em menor grau, por exemplo, oriundos da Bolívia, do Uruguai e do Paraguai, justamente aqueles menores e, em parte, temerosos da enorme projeção brasileira sobre eles (TRIAS, 1967; LAÎ́NO, 1979; GOSALVEZ, 1974).

Não foi, portanto, gratuitamente que o quarteto da geopolítica brasileira recebeu privilegiada atenção não elogiosa em todo o tempo. Nos anos mais recentes, desde meados do século passado, notam-se críticas mais fortes sobre as políticas brasileiras no plano regional, tendo como marco temporal o instante em que as Forças Armadas assumiram o poder.

No continente passou-se a identificar tudo o que foi feito desde 1964 pelo governo brasileiro, como tentativas de criação de políticas com finalidades de hegemonia regional, apoiadas em critérios estritamente geopolíticos. Esse exagerado discurso antibrasileiro, com certeza, pode ser atribuído, em grande parte, ao avanço dos indicadores brasileiros que passaram a ser relevantes, aumentando o distanciamento econômico e estratégico entre os países componentes da Bacia do Prata.

Mas é bem verdade, também, que muitos discursos ufanistas foram feitos por representantes brasileiros, demonstrando que as críticas, afinal, não eram tão desprovidas de fundamento, embora as políticas apregoadas tenham sido pouco ou jamais concretizadas de fato pelos governos que se revezaram no poder.

\footnotetext{
(4) Inicialmente, a obra de Mário Travassos intitulava-se Aspectos Geográficos Sul-Americanos, quando foi publicada pela primeira vez em 1931. A partir da 4. ed., o título foi alterado para Projeção Continental do Brasil. São Paulo: Nacional, 1947, que espelharia melhor o conteúdo da obra.

(5) Essa é uma analogia à teoria desenvolvida por Halford Mackinder, sobre o "coração do mundo", o denominado "pivô geográfico da História”. Desse autor, consultar Mackinder (1962). Consultar também Tambs (1965. p. 31-49).

(6) Sobre a Antártica, do ponto de vista brasileiro, ver Castro (1976), Menezes (1982). Ver também Villa (2004), Colacrai de Trevisan (1998).
} 
Várias explicações poderiam ser aqui mencionadas: em primeiro lugar porque nem sempre grupos que advogavam o aumento de poder nacional para suplantar países como a Argentina estiveram no comando do aparato de Estado, a não ser em poucos momentos do regime militar. Ou seja, aqueles que pensavam sob os mesmos prismas da Escola Superior de Guerra (esguianos) e que eram os grandes defensores de propostas geopolíticas, e mais estreitamente ligados às concepções norte-americanas do pós-Segunda Guerra Mundial, nem sempre detiveram controle tal que políticas públicas, nessas constando a externa e a estratégica, pudessem ser realizadas apenas sob referido prisma. Em segundo lugar, as próprias clivagens verificadas durante todo o período do regime militar, com discordâncias e rupturas várias, observadas nos momentos sucessórios.

Deve-se considerar, ainda, que a maior parte das políticas públicas brasileiras foi conduzida durante quase todo o tempo não pelos estrategistas militares, mas por técnicos mais preocupados com a eficácia da máquina administrativa e com as políticas macroeconômicas. Muitos desses sequer tinham lido Golbery do Couto e Silva, nem detinham conhecimento das teorias geopolíticas e estratégicas elaboradas pelos representantes do segmento militar, mas faziam parte da administração pública porque eram identificados política e ideologicamente com o regime autoritário e avessos à influência socialista vigente no governo de João Goulart. Para esses técnicos, chamados de tecnocratas ou tecno-burocratas, o que importava era o andamento da economia, a evolução dos indicadores nacionais, e não estavam preocupados com o fato de que, como consequência, o incremento desses fatores pudesse colocar em plano secundário seus vizinhos.

Todavia, o fato de diversos representantes tanto do meio esguiano quanto de outros setores ligados ao planejamento estratégico, incluindo diplomatas, produzirem obras que defendiam a projeção do país, levando em consideração as variáveis geográficas, serviu de pretexto para a construção de agressivo discurso antibrasileiro, chamando-o de imperialista, subimperialista, de país-chave a mando dos Estados Unidos, de gendarme continental, etc.

Obras como a do ex-embaixador Álvaro Teixeira Soares, que ocupou durante longo tempo a chefia da Divisão de Fronteiras do Ministério das Relações Exteriores e de outras menos significativas, como a de Paulo Henrique da Rocha Correa falando sobre a divisão das Guianas "a meias" entre a Venezuela e o Brasil, serviam de motivações para que se generalizasse e identificasse tais estudos com as políticas públicas elaboradas a partir de 1964 (TEIXEIRA SOARES, 1973; CORREA, 1965, p. 65-67). Nessa direção, podem ser encontradas críticas variadas, por exemplo, oriundas do centro de estudos do general Juan Enrique Guglialmelli que, por meio de sua publicação, Estratégia, elegia o Brasil como o grande país imperialista do continente. Na concepção dos vizinhos, a única preocupação brasileira em termos regionais sempre foi a de definir-se como grande potência.

As próprias referências, inclusive em planos de desenvolvimento nacional, em parte, davam, porém, margens a que interpretações desse tipo fossem feitas, com justa razão. ${ }^{(7)}$ Com esse espírito, portanto, a única visão desenvolvida pelo Brasil seria a de construção de um poder forte, individual, que fizesse do país uma potência incontestável.

(7) No período Médici, esse tipo de discurso esteve bem presente quando se falou explicitamente no Brasil Potência até o final do século XX. Cf. Presidência da República (1970). 
Sob essa ótica, não sobraria margens para políticas de colaboração ou de integração regional, em uma concepção verdadeiramente favorável ao aumento das capacidades dos países latino-americanos diante de uma realidade mundial que sempre deixou a região completamente afastada dos grandes centros de decisão. Assim, o Brasil não estaria preocupado com a região, mas apenas com seu próprio destino. Nesse caso, políticas integrativas ocupariam espaços reduzidos ou simplesmente inexistiriam na conduta brasileira.

\section{A integração regional na agenda brasileira}

Embora se possa creditar grande parte de razão às criticas latino-americanas, tanto por parte dos geopolíticos e estrategistas quanto pelos próprios governantes, não se pode afirmar que as preocupações das políticas brasileiras privilegiaram tão somente as concepções duras das relações internacionais.

Se de um lado essa é uma realidade a que todos os países se dedicam, não importando seus tamanhos, seus poderes e as latitudes onde se encontram, não é menos verdadeiro que políticas de cooperação coexistem simultaneamente. No caso latino-americano, essa é uma verdade factual fácil de se observar. Ao mesmo tempo em que disputas intensas se davam não apenas durante a vigência do regime militar brasileiro (1964-1985), mas inclusive em outros momentos, antes e depois desse período histórico, o fato é que políticas em direção contrária também se sucediam.

Sempre houve duas percepções em termos brasileiros. De um lado, políticas que visam a fortalecer seu poder nacional, integrando concomitantemente o território e, como consequência, o aumento de suas projeções no plano regional ou mesmo com ambições maiores de ocupar espaços cada vez mais consideráveis no âmbito do sistema internacional. Aliás, essa sempre foi, independentemente das críticas regionais ou das análises estritamente geopolíticas, uma aspiração nacional de todos os tempos, podendo-se mencionar, como exemplo, a pretensão brasileira de ocupar uma vaga permanente como membro do Conselho de Segurança Nacional da Liga das Nações, quase um século atrás (GARCIA, 2000; SANTOS, 1996).

De outro lado, o fato de pertencer a América do Sul; geograficamente, essa sempre foi área de atuação forte do governo brasileiro, motivo pelo qual não apenas o aumento da capacidade nacional foi considerado, mas igualmente levado em conta a necessidade de participar ativamente das dificuldades da região como um todo, diante dos constrangimentos observados nas relações com os demais países mormente do Hemisfério Norte, aqueles considerados altamente industrializados.

Por isso, políticas de colaboração sempre aconteceram, apesar das dificuldades bilaterais ou multilaterais regionais, das modalidades de governo ou das disputas pela construção de barragens ou de fábricas junto às fronteiras. Tanto no caso de Itaipu quanto das divergências entre uruguaios e argentinos em torno da construção da indústria de processamento de papel, tais obras inscrevem-se dentro das medidas que cada país adota, que nem sempre encontram ressonância favorável do outro lado, mas que fazem parte do quotidiano de todas as nações. 
Nesse sentido, no pós-Segunda Guerra Mundial, inúmeras iniciativas podem ser observadas, tomadas pelo governo brasileiro, ou em conjunto, ou mesmo oriundas de outras nações do continente, que tiveram pleno apoio das autoridades de Brasília, em prol de uma política regional, seja na Bacia do Prata, seja na Bacia Amazônica ou abrangendo todo o continente sul-americano.

Mesmo com a Argentina, ainda distante dos momentos mais tensos que caracterizaram as negociações tripartites entre Brasília, Buenos Aires e Assunção, em torno da construção da barragem de Itaipu, firmou-se, em 23 de abril de 1969, o chamado Tratado da Bacia do Prata. ${ }^{\left({ }^{(}\right)}$Envolvendo Argentina, Bolívia, Brasil, Paraguai e Uruguai, justamente com finalidade de cooperar em relação aos problemas comuns que diziam respeito a esta parte do mundo, é que se reuniram em Brasília os chanceleres dos países citados. Naquela ocasião, os países prometeram conjugar esforços para "promover o desenvolvimento harmônico e a integração física da Bacia do Prata e de suas áreas de influência direta e ponderável". Tópicos como navegação, aproveitamento dos cursos de água, cooperação em educação, saúde, aperfeiçoa-mento dos meios de transportes, instalação de indústrias de interesse para o desenvol-vimento da Bacia foram alguns dos assuntos que deveriam ser objeto de cooperação (MRE, 1969. p. 149-152).

No Norte do país, por iniciativa brasileira, firmou-se, em 3 de julho de 1978, o Tratado de Cooperação Amazônica (TCA), com mais sete países da região. Por esse instrumento, os Estados amazônicos concordavam que era "necessário manter o equilíbrio entre o crescimento econômico e a preservação do meio ambiente". E chamavam atenção para o fato de que "o uso e aproveitamento exclusivo dos recursos naturais em seus respectivos territórios é direito inerente à soberania do Estado". Mas, nem por isso, abriam mão da cooperação de órgãos internacionais e da necessidade de criar uma infraestrutura física, sobretudo em transportes e comunicações entre seus paises (MRE, 1978, p. 9-18).

Em 1986, por meio de uma proposta do Ministério das Relações Exteriores, o Atlântico Sul foi considerado área livre de conflitos, pela própria Organização das Nações Unidas, com a criação da Zona de Paz e de Cooperação no Atlântico Sul (ZOPACS), abrangendo os países ribeirinhos do grande lago atlântico (MRE, 1986c).

Tais fatos demonstram que, ao lado das divergências, políticas de cooperação foram implementadas, em regimes políticos diferentes, mas com finalidades que seguiam na mesma direção de propiciar melhores condições aos países sul-americanos em determinados tópicos. Algumas medidas dessa natureza tiveram interpretações distintas dentro das próprias instâncias de decisão governamentais brasileiras. Por exemplo, no caso da ZOPACS, o Ministério das Relações Exteriores e as Forças Armadas tiveram de chegar a um acordo acerca do real alcance desse instrumento, inclusive fazendo distinções conceituais sobre o que se deveria entender por não militarização e desmilitarização. Na ocasião, as autoridades brasileiras acordaram entre si que:

É importante, pois, que fique claramente entendido que o conceito de não militarização da área por países a ela estranhos não pode ser confundido com a desmilitarização, no

(8) Sobre os problemas verificados por ocasião da construção dessa barragem hidroelétrica, consultar: Caubet (1991), Betiol (1983), Carletto de Lima (2006). 
sentido de redução da capacidade de atuação militar dos países da região. Nesse contexto, a iniciativa brasileira para o Atlântico Sul, ao acentuar o papel próprio dos países da área, tem como princípio que cabe a esses países assumir maiores responsabilidades para a defesa da paz e da segurança regionais, sendo necessário, por conseguinte, que se disponha dos meios de atuação para tanto" (MRE, 1986. p. 75).

Esses três exemplos mostram o governo brasileiro agindo em três frentes distintas geograficamente, mas que atendem o continente como um todo: Bacia do Prata, Bacia Amazônica e Atlântico Sul. Cada um com seus objetivos específicos, mas procurando atuação conjunta para resolver problemas que afetavam a todos, diante das adversidades mais amplas. Possivelmente, nenhum deles conseguiria superar individualmente, ou em negociações bilaterais, dificuldades que se apresentavam, sendo que tais acordos perseguiam o objetivo de demonstrar uniformidade na defesa de interesses dos países da região, em oposição aos de outros que poderiam se fazer sentir de maneira adversa ao continente sul-americano.

Contudo, a demonstração de que a visão de cooperação e integração sempre esteve presente na perspectiva brasileira, vale lembrar as duas maiores iniciativas na região, antes do término do período da Guerra Fria. Trata-se de duas propostas ambiciosas que, por motivos distintos, não conseguiram sobrepor-se aos obstáculos surgidos: uma delas, a Associação Latino-Americana de Livre Comércio (ALALC), criada em 18 de fevereiro de 1960, e sua sucessora, a Associação Latino-Americana de Integração (ALADI), formalizada em 12 de agosto de 1980, ambas constituídas em Montevidéu.

Quando se criou a ALALC, as nações latino-americanas estavam "convencidas de que o fortalecimento das economias nacionais contribuirá para o incremento do comércio dos países latino-americanos entre si e com o resto do mundo". Motivados por esse entendimento, encontraram-se, portanto, "animados do propósito de unir seus esforços em favor de uma progressiva complementação e integração de suas economias com base numa efetiva reciprocidade de benefícios" e decidiram "estabelecer uma zona de livre comércio"..9) As dificuldades encontradas, tanto no plano interno quanto em termos da conjuntura regional, com a intervenção norte-americana na região, além dos propósitos otimistas difíceis de serem cumpridos em tempo reduzido, conspiraram para que essa iniciativa jamais conseguisse alcançar seus intentos (BARBOSA, 1991).

Por sua vez, a ALADI, ao ser constituída, era percebida pelos países membros como uma necessidade de "renovar o processo de integração latino-americana e estabelecer objetivos e mecanismos compatíveis com a realidade da região". Entendia-se a necessidade de "assegurar um tratamento especial para os países de menor desenvolvimento econômico relativo", ao mesmo tempo que se considerava igualmente necessário "contribuir para a obtenção de um novo esquema de cooperação horizontal entre países em desenvolvimento e suas áreas de integração". ${ }^{(10)}$

O tempo também se encarregou de reduzir as expectativas da sucessora da ALALC, principalmente levando-se em conta as duras realidades enfrentadas pelo continente nos anos 80 , além das grandes transformações verificadas com o término da Guerra Fria. Com

(9) Ver a íntegra do Tratado de Montevidéu de 1960, em Revista Brasileira de Política Internacional (1960. p. 142-159). (10) Cf. a íntegra do Tratado de Montevidéu, de 1980, em Ministério das Relações Exteriores (1980. p. 133-142). 
o fim do Acordo Geral sobre Tarifas Aduaneiras e Comércio (GATT) e o advento da Organização Mundial do Comércio (OMC), em um novo contexto que passou a orientar as políticas e os negócios internacionais, países como os latino-americanos, mas não apenas esses, sentiram-se obrigados a rever suas políticas domésticas e também a repensar sua inserção em outros termos, diferentes dos que até então vigoravam.

No período pós-Guerra Fria, a criação do Mercado Comum do Sul (MERCOSUL), em 1994, apesar de suas dificuldades, tem encontrado forte respaldo do governo brasileiro, procurando unificar a região, que será objeto do próximo tópico.

\section{CoOperação E INTEgRAÇão No PÓS-REgIME MILITAR}

Grandes mudanças se sucederam na década de 1980 com o encerramento dos regimes autoritários na América do Sul. Na Argentina, o fracasso da guerra pela retomada das Malvinas em 1982 colocou a pique o modelo então prevalente. De um lado, o orgulho portenho ficou ferido com a derrota para o Reino Unido, contabilizou centenas de baixas e não recobrou o território reivindicado. De outro, o retorno à democracia e a assunção do poder por Raul Ricardo Alfonsin facilitaram políticas de aproximação com o Brasil.

No caso brasileiro, o encerramento do ciclo militar havia sido já negociado desde meados da década de 1970 com a transição pactuada. A distensão chegara ao fim, ainda que lenta e gradualmente, conforme fora proposto pelas autoridades, embora o novo governo tivesse sido eleito de forma indireta pelo Colégio Eleitoral. De nada serviram as mobilizações populares e a campanha pelas eleições diretas.

Resultado imediato dessas alterações foi uma mudança de comportamento no cenário regional, agora com presidentes civis nos dois maiores países do Cone Sul. Por ocasião da inauguração da Ponte Internacional Tancredo Neves, que liga Porto Meira (Brasil) a Puerto Iguazu (Argentina), em 29 de novembro de 1985, Raul Alfonsin e José Sarney assinaram, no outro dia, a "Declaração de Iguaçu". Por intermédio desse documento, os dois governos concordavam em "conjugar e coordenar os esforços para a revitalização das políticas de cooperação e integração entre as nações latino-americanas". Com esse intuito "expressaram firme vontade política de acelerar o processo de integração bilateral, em harmonia com os esforços de cooperação e o desenvolvimento regional". Para atingir tal intento, criaram uma "Comissão Mista de Alto Nível para Cooperação e Integração Econômica Bilateral, para examinar e propor programas, projetos e modalidades de integração econômica”. ${ }^{(11)}$

No ano seguinte, Sarney viajou à Argentina entre 28 a 30 de junho, enquanto Alfonsin retribuiu a visita entre 8 e 11 de dezembro, quando foram assinados os protocolos de integração no Palácio do Planalto no dia 10. Pelos 17 protocolos estabeleceram-se variadas formas de cooperação, entre as quais podem ser mencionadas: acordo financeiro, empresas binacionais, segurança nuclear, transportes, biotecnologia, setores energéticos. ${ }^{(12)}$

(11) Cf. Declaração de Iguaçu (Ministério das Relações Exteriores, 1985. p. 28-32).

(12) Os protocolos, em sua íntegra, bem como as negociações e os discursos de ambos os presidentes, podem ser encontrados em Ministério das Relações Exteriores (1986. p. 13-25; 1986. 1987). 
Para o entendimento desse quadro, necessariamente, deve-se considerar outros elementos tão ou mais importantes do que a redemocratização de ambos os países. A própria dinâmica observada no cenário internacional conduziu a realização de tal processo, não apenas na Bacia do Prata, mas em todo o continente latino-americano. Análises diversas já explicaram a contento tais processos, motivo pelo qual escusamo-nos de aqui comentá-los com mais detalhes. ${ }^{(13)}$

Vale lembrar, entretanto, que a proximidade do final da Guerra Fria, ainda que não tivesse sido estabelecida formalmente (nem esperada com tal velocidade), já dava sinais de esgotamento do modelo soviético, com as próprias mudanças internas conduzidas por Mikhail Gorbachev, com a Glasnost e a Perestroika. De maneira sucinta, pode-se dizer que o surgimento de competidores fortes economicamente, na arena internacional, como a Alemanha e o Japão, além da insuficiência de instâncias multilaterais como o GATT (substituída pela Organização Mundial do Comércio em 1994), que não atendia mais a contento aos interesses de potências como os Estados Unidos, todos esses fatores em conjunto levaram à necessidade de transformações no plano regional, afetando, portanto, países como Brasil e Argentina.

Ainda que problemas ocorressem nos anos 1980, que atingiam de formas diferentes as duas nações, nem por isso desistiu-se de implementar os protocolos de integração, pelo menos em parte.

As agudas dificuldades enfrentadas pelo governo de José Sarney, com taxas extremamente elevadas de inflação ao final da década, converteram-se em fator inibidor para que políticas mais consistentes pudessem ser estabelecidas tanto no âmbito doméstico quanto em moldes regionais. Internamente, o custo da dívida pública se fez sentir, e o montante acumulado de 115 bilhões de dólares tornou-se forte indicador da incapacidade de o país resolver seus problemas, tendo inclusive declarado moratória unilateralmente em 1987.

Contam-se nesses anos os fracassos dos Planos Cruzados I e II em 1986, o Plano Bresser de 1987 e o Plano Verão de 1988. No plano regional, tornou-se inviável acelerar processos de colaboração mais sólidos, justamente devido às diferenças observadas entre Buenos Aires e Brasília, quando a moeda brasileira sofreu grande desgaste, com o país enfrentando índice inflacionário elevado, constituindo-se esses em elementos bloqueadores de intercâmbio mais efetivo.

Apesar dos protocolos, em todos os anos posteriores não necessariamente a Casa Rosada considerava o Palácio do Planalto a melhor alternativa para parcerias, como se observou nos mandatos de Carlos Saul Menem, quando fez a demanda de membro associado da Organização do Tratado do Atlântico Norte (OTAN), enviando carta ao presidente norte-americano Bill Clinton, em 8 de julho de 1999.

Essa foi uma atitude amadurecida ao longo do tempo, porque em Buenos Aires se havia realizado, em 12 e 13 de outubro de 1993, um grande evento para discutir a segurança global, ao qual comparecera o próprio secretário-geral adjunto da OTAN, embaixador

(13) A bibliografia sobre o tema é extensa e o que mais tem merecido atenção nos últimos anos, sob distintos enfoques. Apenas a título de ilustração, consultar: Almeida (1993), Lavagna (1998), Vaz (2002). 
Amedeo de Franchis. No discurso de encerramento do seminário, Carlos Menem assim se referiu ao mesmo: "que sea éste un testimonio más del interés de mi gobierno en continuar y profundizar el proceso de acercamiento y consultas con la OTAN". E lembrava, ainda, mais dois fatos: o primeiro, que a Argentina havia participado da Guerra do Golfo, cumprindo as decisões do Conselho de Segurança; segundo, que a segurança global do futuro deveria estar apoiada nas instituições vigentes, a ONU e a OTAN (MENEM, 1994, p. 15).

A Rodada GATT do Uruguai também foi um dos fatores mais importantes ocorridos na década em território sul-americano, que se converteu em forte elemento para que políticas com outras características fossem adotadas, visando a atender às necessidades comuns $\mathrm{e}$ fazer frente ao cenário que se apresentava.

O surgimento do Mercado Comum do Sul (MERCOSUL) inscreve-se nesse cenário, reunindo inicialmente os quatro componentes da Bacia do Prata: Argentina, Brasil, Paraguai e Uruguai. Apesar das evidentes assimetrias de poder, tornava-se claro que a cooperação deveria ser o caminho trilhado pelas nações sul-americanas. Os anos que se seguiram mostraram que, apesar da vontade e da necessidade de colaboração, em instituições mais amplas, os interesses particulares de cada país nunca deixaram de ser explicitados e se converteram em fator desagregador de tal iniciativa.

Nada diferente do que ocorrera em momentos distintos com a própria ALALC e a ALADI, ainda que essas reunissem todos os países do continente. Deve-se, entretanto, ponderar que, no caso mais regional do Cone Sul, impossível seria resolver em período tão curto como o proposto problemas que há dezenas de anos afetavam os países da região, que sempre disputaram suas influências. Além de terem de tratar de suas próprias querelas e dificuldades domésticas, sempre agudas, com grandes disputas eleitorais, as diferenças a serem aparadas converteram-se em tarefa grandiosa, principalmente visando a uma efetiva integração.

Apesar disso, colaborações podem ser observadas mesmo no âmbito militar, por exemplo, por meio dos simpósios de estudos estratégicos dos Ministérios do Estado-Maior das Forças Armadas de ambos os países, em Buenos Aires e São Paulo, já no fechar da década de $1980 .{ }^{(14)} \mathrm{Se}$, de um lado, aumentavam-se os graus de confiança, por intermédio de intercâmbios que uniam civis e militares, nem por isso áreas sensíveis como as próprias políticas externa e de defesa, envolvendo, justamente, setores vitais, tiveram avanço mais significativo como se poderia esperar, ou se desejaria alcançar.

Pode-se, porém, afirmar, por outro lado, que tipos de contribuição nesse sentido, entre argentinos e brasileiros, resultaram, posteriormente, em bons dividendos. Os dois países firmaram, em agosto de 1991, o Acordo para o Uso Exclusivamente Pacífico da Energia Nuclear, que criou a Agência Brasileiro-Argentina de Contabilidade e Controle de Materiais Nucleares (ABACC). Em 1994, brasileiros e argentinos colocaram suas assinaturas em acordo realizado pela ABACC e a Agência Internacional de Energia A tômica (AIEA) para Aplicação de Salvaguardas, conhecido como Acordo Quadripartite

\footnotetext{
(14) As intervenções apresentadas nessas duas oportunidades podem ser facilmente encontradas. Os textos do primeiro simpósio realizado em Buenos Aires, em abril de 1987, foram publicados pela Política e Estratégia (1987); os do segundo simpósio realizado em São Paulo, em abril de 1988, estão em Política e Estratégia (1988).
} 
Outras medidas podem ser contabilizadas. Em um dos casos, o Brasil, sentindo-se pressionado pela necessidade de pensar o novo quadro regional, ratificou, em maio de 1994, o Tratado de Tlatelolco de Prescrição de Armas Nucleares na América Latina e, posteriormente, firmou o Tratado de não Proliferação de Armas Nucleares (TNP), no governo de Fernando Henrique Cardoso, em setembro de 1998.

Como se pode recordar, o governo brasileiro se recusava a adotar esse procedimento desde 1968, quando o TNP foi proposto. O Brasil não apenas agiu dessa forma como ainda denunciou a tentativa do que chamava de "congelamento do poder mundial", acusando os Estados detentores de tal tecnologia de quererem monopolizá-lo (ARAUJO CASTRO, 1972). Nesse caso, estava se impedindo o acesso dos países em desenvolvimento à tecnologia nuclear, prejudicando-os, porque essa poderia ser utilizada com finalidades médicas. Claro que $o$ acesso ao restrito clube nuclear também representaria um salto qualitativo em termos de poder nacional, podendo desequilibrar as relações regionais.

Apesar de alguns pontos positivos, a integração regional, pelo menos nessa parte do continente, não avançou a contento e ficou distante dos objetivos inicialmente propostos no tempo indicado, assim como também não progrediu em outras direções, visando aperfeiçoá-la ou torná-la mais adequada às realidades locais, atendendo muito mais aos interesses individuais, que se fizeram cada vez mais fortes.

Foi justamente na defesa de suas demandas particulares que os países membros mais se bateram, como se pode observar na campanha de reeleição de Saul Menem, quando esse defendeu a indústria automobilística de seu país, ou as divergências sobre a exportação dos produtos hortifrutigranjeiros, originando o conflito que se designou "salada de frutas". Os interessados no entendimento desses aspectos do relacionamento argentino-brasileiro não encontrarão dificuldades para arrolar, às dezenas, as ressalvas feitas por ambos os países, cada um buscando favorecer seus agentes domésticos, seja na indústria automotriz, no setor têxtil, de brinquedos, lácteos ou de carnes.

$\mathrm{Na}$ realidade, acordos dessa natureza, feitos com certa sofreguidão, tinham poucas chances de apresentarem bons resultados de imediato. É o que se passa normalmente com a construção de instituições multilaterais, em tempos de paz. Em momentos adversos, com conflitos regionais ou internacionais em andamento, a pressa é um dos elementos fundamentais que orientam a formação das instituições, já que o tempo é exíguo e não se pode perdê-lo, sob risco de ver comprometida a segurança dos países diretamente interessados. O contrário se sucede em épocas em que o conflito não está localizado no centro da discussão. Nesse caso, há necessidade de se discutir pormenorizadamente cada item, atender aos agentes que pressionam internamente a Chancelaria e o Executivo como um todo, o que demanda cuidados (para não perder apoios eleitorais) e tempo indefinido para se chegar a um acordo que a todos satisfaça. Daí as dificuldades encontradas não apenas no caso do Mercosul, mas das outras instâncias com características semelhantes.

\section{O NOVO CONTEXTO: UMA AGENDA AFIRMATIVA?}

Nos últimos três lustros, que cobrem os dois mandatos de Fernando Henrique Cardoso e a metade do segundo governo de Luiz Inácio Lula da Silva, acusações têm sido feitas de 
ambos os lados (presidente e ex-presidente), procurando mostrar o segundo que o primeiro pouca atenção dedicou à América do Sul, portanto, com interesses limitados na integração regional. Do lado de Cardoso, críticas são feitas às políticas implementadas pelo governo Lula, dando a entender que tudo se retém mais à retórica do que a uma política eficaz e com resultados satisfatórios.

Não se deve estranhar comportamentos dessa natureza. É normal que isso ocorra, por causa das disputas eleitorais permanentes entre os partidos que ambos representam, na busca ou pela continuidade do poder.

Provavelmente, uma análise mais distanciada de ambos os lados dará razão às duas partes. O primeiro governante não foi, com certeza, pródigo nas políticas integrativas, ainda que a feitura do Mercosul tenha recebido guarida sob sua administração. Por sua vez, o segundo não foi, e nunca isso será considerado fato verdadeiro, o precursor do aprofundamento das relações econômicas, políticas, comerciais e estratégicas sul-americanas, porque a região esteve sempre na agenda da política externa brasileira, no decorrer do tempo. Inexplicável seria se isso não acontecesse.

Antes da virada do século, a América Latina como um todo desempenhou papel de relativo interesse para o governo brasileiro. Certamente não se colocou como prioridade primeira do Itamaraty, que preferiu jogar em um cenário mais amplo, por meio do que se convencionou designar "parcerias seletivas". No caso regional, a Argentina, sobretudo em função do Mercosul, continuou recebendo atenção especial, por causa de suas particularidades.

Em traços largos, pode-se dizer que a atuação do Brasil, no cenário latino-americano, insere-se dentro de um quadro mais amplo, de favorecimento ao relacionamento Sul-Sul. Claro que isso também não é novidade na política externa brasileira. Nos anos 70 e 80 o país já se ocupava desses problemas. Podem ser mencionadas as atuações junto ao bloco dos países não alinhados (do qual o Brasil nunca fez parte, a não ser como observador), desde a conferência de $1961 \mathrm{em}$ Belgrado. O Grupo dos 77 do qual participou ativamente desde 1964, quando surgiu a Conferência das Nações Unidas para o Comércio e Desenvolvimento (UNCTAD), foi alvo de especial deferência mormente na década de 1970, ainda que naqueles anos e no início dos 1980 as autoridades nacionais colocassem em dúvida a presença do país nesse grupo ou no Primeiro Mundo, conforme, às vezes, reivindicavam.

Na realidade, pertencer ao Primeiro ou ao Terceiro Mundo foi uma preocupação constante da agenda da política externa brasileira. Houve mesmo oportunidade em que a Chancelaria, por intermédio de seu representante maior, Mário Gibson Barboza, dizia em 1973 não reconhecer a existência do próprio Terceiro Mundo, retificando essa afirmação no último governo militar, quando já se encontrava afastado do cargo (BARBOZA, 1981, p. 16).

Dentro de um contexto geral, a política externa brasileira rotineiramente marcou presença, com as devidas ressalvas, participando das reuniões do bloco dos não alinhados, do grupo maior que aglomerava os países do Terceiro Mundo (incluindo os primeiros) e apoiando as demandas das nações do Sul, ainda que essas não merecessem primazia em várias oportunidades, como no período Médici. 
Nos umbrais do século XXI, uma das alternativas brasileiras foi jogar seu peso no relacionamento dos países do Hemisfério Sul. Contudo, não se deixou de privilegiar as instituições multilaterais ou de fazer parcerias seletivas com algumas nações que despontaram com vigor nos últimos anos, exemplificados pelos casos da África do Sul, Rússia, China e Índia. Seja participando de unidades como G3, G20, IBAS, Grupo do Rio, Comunidade dos Países de Língua Portuguesa (CPLP), Sistema Econômico Latino-Americano (SELA), entre outros, o relacionamento Sul-Sul se fez presente de maneira bastante distinta da verificada até os anos 80 .

Motivos para explicar as novas opções não faltam. Entre essas, o novo contexto regional, as abruptas mudanças observadas com o final da Guerra Fria, além da retomada das próprias demandas do governo brasileiro, com a pretensão de converter o Brasil em um Estado com vontade de "ser importante" não apenas no âmbito regional, mas sobretudo na esfera ampla das relações internacionais, advogando por uma presença permanente no Conselho de Segurança da Organização das Nações Unidas e como membro do G8.

Se, com Fernando Henrique Cardoso, o problema da integração regional se colocou com menos vigor, de outro lado, não se pode simplesmente afirmar que a América do Sul ficou ignorada. Os inumeráveis encontros, ora com os membros participantes do Cone Sul, com os amazônicos ou mesmo em escala mais ampla, por exemplo, por meio das próprias reuniões com os ministros da Defesa das Américas, a partir de 1995, são sinais claros e indicativos de que problemas regionais jamais deixaram de ocupar espaço na pauta governamental brasileira.

No limiar do novo século, com o governo Lula, inquestionavelmente, a atenção para o continente foi redobrada, ainda que merecesse severas críticas desde o primeiro momento de seu mandato, ou até antes, bastando lembrar o imbróglio venezuelano, com a ida àquele país de Marco Aurélio Garcia, futuro assessor especial de Assuntos Internacionais da Presidência da República.

Algumas ressalvas que dizem respeito apenas à região sul-americana podem ser aqui enumeradas: uma se refere à pretensão declarada de o país converter-se em liderança regional, discurso que foi ao longo do tempo sendo diluído, praticamente deixando de existir, pelo menos de maneira enfática, como se verificou nos primeiros anos; declarações como a de Roberto Amaral, titular do Ministério da Ciência e Tecnologia que, na primeira semana do mandato, afirmava que o Brasil estava interessado na confecção de artefatos nucleares; atitude considerada submissa frente ao governo argentino de Nestor Kirchner em todo o tempo; erros de cálculo por falta de conhecimento sobre a situação interna dos países com os quais faz fronteira, por exemplo, na crise energética com o vizinho boliviano; declarações excessivamente informais, como a ocorrida em Arequipa, no Peru, sobre os colonizadores do continente. ${ }^{(15)} \mathrm{A}$ essas podem ser arroladas inúmeras medidas que nem sempre se configuraram como as mais corretas ou que melhores retornos propiciaram, desde o perdão da dívida boliviana ao papel dúbio desempenhado em ocasiões outras em relação à Venezuela e à Colômbia.

(15) Visões sobre as incontáveis viagens e o comportamento presidenciais podem ser encontradas em Scolese (2006) e Rohter (2008). 
No cômputo geral, pode-se creditar a favor do atual governo decisões que caminham no sentido de favorecer não apenas a integração cultural (sobretudo no Cone Sul) como também em termos da própria geografia sul-americana com o Programa de Integração da Infraestrutura Sul-Americana (IIRSA), existente desde 2000, ora manifestando-se de forma reticente com a criação do Banco do Sul (como fez o ministro da Fazenda Guido Mantega em 18 de janeiro de 2007), outras vezes aprovando-o enfaticamente (como fez o presidente Lula, no dia 26 de maio de 2008, por ocasião da UNASUL), ou a Área de Livre Comércio Sul Americana (ALCSA) (SPITZ, 2008; Folha de S. Paulo, 2008). Para várias dessas iniciativas, o governo chegou inclusive a mobilizar e disponibilizar recursos por meio do Banco Nacional de Desenvolvimento Econômico e Social (BNDES), utilizando-o como instrumento de política externa. Com intensidade, manifestou-se contrário à Área de Livre Comércio das Américas (ALCA), por considerar que essa não atendia às expectativas dos países sul-americanos.

A última iniciativa que pode ser mencionada refere-se a criação de um Conselho de Defesa Sul-Americano. O encontro realizado em Brasília, em meados de maio de 2008, contudo, trouxe à mostra novamente as diferenças de pontos de vista sobre temas dessa natureza. Conquanto se houvesse formalizado a União das Nações Sul-Americanas (UNASUL) naquela ocasião, o conselho só se tornou realidade ao final do ano, mas com espaço de ação bastante limitado. A UNASUL nada mais é do que a ideia anterior da Comunidade Sul-Americana de Nações (CASA), que tinha sido proposta em 2004 na cidade de Cuzco, no Peru, mas que não seguiu avante. Posteriormente, em 2007, seu nome foi alterado, quando se realizou, em Caracas, a Primeira Reunião Energética da América do Sul. Dessa vez, em Brasília, conseguiu chegar-se pelo menos a um acordo para que a UNASUL pudesse ser concretizada, apoiada em dois grandes pilares, o Mercosul e a Comunidade Andina de Nações.

Para o presidente Lula, a criação da UNASUL "mexerá com o tabuleiro do poder no mundo", sendo que "nossa América do Sul não será mais um mero conceito geográfico. A partir de hoje é uma realidade política, econômica e social, com funcionalidade própria" (MARIN, PARAGUASSU, 2008). Ou seja, implicitamente, estava admitindo que, apesar de todos os discursos anteriores, o continente não era aquilo apregoado e, pelo contrário, estava bem distante de ser uma voz uníssona. O encontro mostrou isto de forma cristalina. O que se observou foi uma série de divergências e resistências de várias nações sul-americanas, sobre o real alcance desse processo, casos da Colômbia, da Bolívia e do Equador. Contudo, as intenções são boas, como diz o documento de criação da UNASUL:

La Unión de Naciones Suramericanas tiene como objetivo construir, de manera participativa y consensuada, un espacio de integración y unión en lo cultural, social, econó-mico y político entre sus pueblos, otorgando prioridad al diálogo político, las políticas sociales, la educación, la energía, la infraestructura, el financiamiento y el medio ambiente, entre otros, con miras a eliminar la desigualdad socioeconómica, lograr la inclusión social y la participación ciudadana, fortalecer la democracia y reducir las asimetrías en el marco del fortalecimiento de la soberanía e independencia de los Estados.

O tempo novamente será o senhor da razão e mostrará até que ponto mais essa iniciativa estará fadada ao sucesso ou se enfrentará dificuldades semelhantes às que até 
agora sempre prejudicaram o andamento das outras propostas e que impediram que se atingisse os fins almejados. Não se pode, ainda, esquecer o próprio aspecto orçamentário, porque sem recursos assegurados a UNASUL verá restringidas as possibilidades de realizar grandes mudanças, convertendo-se em mero fórum de debates.

De qualquer forma, pode-se dizer que a política do governo Lula tem sido mais assertiva do que as anteriores. A própria ampliação do Mercosul verificada nos últimos anos é um fator positivo que mostra a importância do assunto em termos sul-americanos, se bem que resultados concretos demorarão para ser observados. Deve-se, porém, considerar a existência no continente de outros chefes de Estado que, por meio de posicionamentos vigorosos, têm, pelo menos parcialmente, eclipsado a atuação do governante brasileiro e proposto igualmente mudanças que escapam ao cenário regional mais próximo, por intermédio de políticas mais fortes, objetivando não apenas uma inserção mais favorável em termos globais, mas defendendo grandes transformações no sistema internacional.

Por último, vale lembrar alguns aspectos que têm sido negligenciados em boa parte das análises e até mesmo pelas autoridades em seus encontros com seus parceiros, sobre a integração sul-americana. Referimo-nos às questões técnicas que têm sido alvo de atenção maior dos profissionais das áreas de Ciências Exatas. Assim, itens como integração energética, seja no que se refere à questão do gás natural, seja no campo da energia elétrica, são tópicos importantes que contribuem para uma aproximação de todos os membros da comunidade sul-americana ${ }^{(16)}$

\section{CONSIDERAÇõES FINAIS}

Conforme descrevemos ao longo do texto, a América do Sul se constitui em espaço importante da política externa brasileira. Historicamente, não poderia ser de maneira diferente, por causa dos próprios condicionantes geográficos. Apesar das inúmeras divergências no plano regional com um ou outro vizinho, fundamentalmente acerca de uma disputa por uma possível hegemonia continental, o relacionamento do Brasil com seus vizinhos sempre privilegiou a cooperação. Por isso, a última vez que o país pegou nas armas para defender seus interesses regionais foi na guerra contra o Paraguai (1864-1870), há 144 anos.

Interesses distintos fazem parte do quotidiano das nações, não importando seus tamanhos, porque dificilmente se consegue conciliar de maneira integral aspirações nacionais com projetos regionais. Todavia, mesmo em contextos adversos para os países da região, não seria exagero afirmar que todos eles, apesar das diferenças de demandas e de pontos de vista, apostaram na cooperação e integração como mecanismo para resolver problemas individuais e coletivos. O que, evidentemente, não exclui divergências periódicas.

Em função das assimetrias de poder tanto no plano interno sul-americano quanto no contexto do sistema mundial, seria incorrer em otimismo exagerado esperar que as políticas

(16) Ver abordagens nessa direção em: Lopez Suarez (2006) e Cabral (2004).

106 
desenvolvidas ou sugeridas pelos Estados maiores da região contemplem efetivamente os interesses de todos com igual intensidade. Isso se verifica de forma parecida no âmbito mundial.

A retórica tem sido mais forte do que a prática real, daí os esforços ainda serem considerados insuficientes para projetar a região no tabuleiro do poder global. Na verdade, existem dúvidas bastante fortes para se imaginar a América do Sul como bloco uniforme, com pensamento harmônico, ocupando lugar de destaque em um contexto mais geral, conforme pode ser observado na construção da UNASUL. O mais razoável é que se pense e se visualize alguns países da região desempenhando papel de destaque individualmente.

Apesar dos discursos de colaboração e cooperação feitos com grande frequência, deve-se ponderar o contexto em que são realizados, quase sempre obedecendo a mera formalidade protocolar, e muito longe de espelhar os verdadeiros caminhos que cada país está percorrendo. A própria existência de blocos sub-regionais que têm operado com eficácia maior, em um cenário geográfico mais limitado, seria claro exemplo da incapacidade de se juntar todos os países sul-americanos em uma única e grande empreitada, com chances de atuarem conjugadamente e com sucesso.

Os países, sobretudo os de maiores indicadores, abusam da retórica, como não poderiam deixar de fazê-lo, buscando fundamentalmente lucros individuais, utilizando as instituições multilaterais quase que apenas como mero instrumento de suas políticas. Contudo, e apesar disso, não se pode afirmar - em face das experiências vividas no último meio século que políticas de colaboração, visando, no limite, a uma integração real, não tenham ocorrido. Se chegaram a um bom termo ou perderam-se no meio do caminho, sabidamente esse já é um outro problema que a História se encarregará de explicar.

No caso brasileiro, entretanto, seria injusto afirmar que o país evitou apostar na colaboração como um mecanismo eficaz para resolver não apenas seus problemas individuais, mas também os do continente sul-americano como um todo. Pelo contrário, suas propostas regularmente caminharam nessa direção. Se, todavia, as intenções foram no sentido de realmente integrar o continente ou de apenas utilizá-lo para alavancar seus projetos, são dúvidas que merecem atenção e que necessitam ser melhor investigadas. O Brasil não destoa, não se diferencia dos demais países, por isso também age sempre e, primeiramente, de acordo com seus próprios interesses, implementando as políticas que lhe são mais convenientes.

\section{REFERÊNCIAS BIBLIOGRÁFICAS}

ALMEIDA, Paulo Roberto. O Mercosul no contexto regional e internacional. São Paulo: Aduaneiras, 1993.

BARBOSA, Rubens Antonio. América Latina em perspectiva: a integração regional — da retórica à realidade. São Paulo: Aduaneiras, 1991.

BARBOZA, Mário Gibson. O Brasil no mundo e na região, na década de 80. Revista Brasileira de Política Internacional, Rio de Janeiro: IBRI, ano XXIV, n. 93-96, p. 14-19, 1981. 
Shiguenoli Miyamoto — Cadernos PROLAM/USP (Ano 8 - Vol. 1 - 2009) p. 89-110

BBC BRASIL. O Brasil sob os olhos da América do Sul. Disponível em: <http://www.bbc.co.uk/ portuguese/especial/1454_americadosul/index.shtml> Acesso em: 10.5.2008.

BETIOL, Laércio. Itaipu, modelo avançado de cooperação internacional na Bacia do Prata. Rio de Janeiro: Fundação Getulio Vargas, 1983.

BLANCO, Ricardo Roman. Las bandeiras. Instituciones bélicas americanas. Brasília: Universidade de Brasília, 1966.

CABRAL, Lígia Maria Martins (coord.). Energia elétrica e integração na América do Sul. Rio de Janeiro: Centro da Memória da Eletricidade no Brasil, 2004.

CANCOGNI, Manlio; BORIS, Ivan. Solano Lopez, o Napoleão do Prata. Rio de Janeiro: Civilização Brasileira, 1975.

CASTRO, João Augusto Araújo. O congelamento do poder mundial. Revista Brasileira de Estudos Políticos, Belo Horizonte, UFMG, n. 33, p. 7-30, jan. 1972.

CASTRO, Therezinha de. Rumo à Antártica. São Paulo: Freitas Bastos, 1976.

CAUBET, Christian G. As grandes manobras de Itaipu. São Paulo: Acadêmica, 1991.

CORREA, Paulo Henrique da Rocha. O Brasil e as Guianas. Catanduva: IBEL, 1965.

DORATIOTO, Francisco. Maldita guerra: nova história da Guerra do Paraguai. 2. ed. São Paulo: Companhia das Letras, 2002.

FOLHA DE S. PAULO. Lula cogita criação de moeda e banco central únicos na América do Sul. Folha on Line, 26 de maio de 2008, 8h27m. Disponível em: <http://www 1.folha.uol.com.br/folha/ dinheiro/ult91u405354.shtml> Acesso em: 27.5.2008.

GARCIA, Eugênio Vargas. O Brasile a Liga das Nações (1919-1926). Por to Alegre/Brasília: UFRGS/ Fundação Alexandre de Gusmão, 2000.

GOSALVEZ, Raul Botelho. Proceso del subimperialismo brasileño. 2. ed. Buenos Aires: Universitária, 1974.

HALFORD, Mackinder. Democratic ideals and reality. New York: W. W. Norton, 1962.

HAUSMANN, Ricardo. Informe 2000. Desarrollo mas allá de la economia. Washington: Banco Interamericano de Desarrollo, 2000.

HOLANDA, Sérgio Buarque de. Caminhos e fronteiras. São Paulo: Companhia das Letras, 1994.

Monções. 2. ed. São Paulo: Alfa-Omega, 1976.

LAINO, Domingo. Paraguai - fronteiras e penetração brasileira. São Paulo: Global, 1979.

LAVAGNA, Roberto. Argentina, Brasil, Mercosur. Una decisión estratégica 1986-2001. Buenos Aires: Ciudad Argentina, 1998.

LIMA, Ivone Teresinha Carletto de. Itaipu. As faces de um megaprojeto de desenvolvimento (1930-1984). Marechal Cândido Rondon. Paraná: Germânica, 2006.

MARIN, Denise Chrispin; PARAGUASSU, Lisandra. Entraves marcam criação de entidade para unir América do Sul. O Estado de S. Paulo, p. A-4, 24 maio 2008.

MENEM, Carlos Saul. In: FONTANA, Andrés (coord.). Argentina - OTAN - perspectivas sobre la seguridad global. Buenos Aires: CARI/Grupo Editor Latinoamericano, 1994.

MENEZES, Eurípedes Cardoso de. A Antártica e os desafios do futuro. Rio de Janeiro: Capemi, 1982. 
MINISTÉRIO DAS RELAÇÕES EXTERIORES. MRE. Tratado de cooperação amazônica. Brasília: MRE, 1978.

Documentos de política externa. Brasília: MRE/Divisão de Documentação/Seção de Publicações, v. III, 1969.

. Resenha de política exterior do Brasil, Tratado de Montevidéu de 1980. Brasília: MRE, n. 26, p. 133-142, jul./set. 1980.

. Resenha de política exterior do Brasil, Declaração de Iguaçu, Brasília: MRE, n. 47, p. 28-32, out./dez. 1985.

. Resenha de política exterior do Brasil, Brasília, n. 51, p. 13-25, out./dez. 1986.

Visita do Presidente José Sarney à Argentina - 28 a 30 de julho de 1986. Brasília: Centro de Documentação/DCO, 1986.

Resenha de política exterior do Brasil. Edição suplementar sobre Zona de Paz e de Cooperação no Atlântico Sul. Brasília: MRE, dez. 1986.

Visita do Presidente da Argentina Raúl Alfonsin ao Brasil - 8 a 11 de dezembro de 1986. Brasília: Centro de Documentação/DCO, 1987.

POlítica E ESTRATÉGiA. São Paulo: Centro de Estudos Estratégicos/Convívio, v. V, n. 3, jul./set. 1987;

. São Paulo: Centro de Estudos Estratégicos/Convívio, v. VI, n. 3, jul./set. 1988.

POMER, Leon. A guerra do Paraguai. Um grande negócio. São Paulo: Global, 1981.

PRESIDÊNCIA DA REPÚBLICA. Metas e bases para a ação do governo. Brasília: IBGE, 1970.

REVISTA BRASILEIRA DE POLÍTICA INTERNACIONAL. Tratado de Montevidéu de 1960. Rio de Janeiro, IBRI, ano III, n. 10, p. 142-159, jun. 1960.

ROHTER, Larry. Deu no New York Times. Rio de Janeiro: Objetiva, 2008.

SANTOS, Norma Breda. Le Brésil et la Société des Nations (1920-1926). 1996. Tese (Doutorado) Université de Généve, Institut Universitaire des Hautes Études Internationales, 1996.

SCOLESE, Eduardo; NOSSA, Leonencio. Viagens com o presidente. Dois repórteres no encalço do Planal to ao exterior. São Paulo: Record, 2006.

SOARES, Álvaro Teixeira. História da formação das fronteiras brasileiras. 3. ed. Rio de Janeiro: Biblioteca do Exército, 1973.

SPITZ, Clarice. Mantega descarta criação do Banco do Sul e defende BNDES. Disponível: <http:// www 1.folha.uol.com.br/folha/brasil/ult96u88756.shtml> Acesso em: 15.5.2008.

SUAREZ, Lizett Paola Lopez. O papel das petroliferas para o desenvolvimento da integração energética: a formação do mercado de gás natural na América do Sul. Campinas, 2006. Dissertação (Mestrado em Planejamento de Sistemas Energéticos) — Faculdade de Engenharia Mecânica da Universidade Estadual de Campinas, 2006.

TAMBS, Lewis. Geopolitical factors in Latin America. In: BAILEY, Norman (ed.). Latin America: politics, economics and hemisphery security. New York: Praeger, 1965.

TAUNAY, Afonso d'Escragnolle. História das bandeiras paulistas. 3. ed. São Paulo: Melhoramentos, 1975. v. 3.

TREVISAN, Miriam Colacrai de. El Ártico y la Antártida. Rosário: CERI/CECAR, 1998. 
TRIAS, Vivian. Imperialismo y geopolítica na América Latina. Montevideo: El Sol, 1967.

VAZ, Alcides Costa. Cooperação, integração e processo negociador. A construção do Mercosul. Brasília: IBRI/FUNAG, 2002.

VILLA, Rafael A. Duarte. A Antártida no sistema internacional. São Paulo: Hucitec, 2004. 